\title{
Physical and Optical Properties of Poly(3-AlkylThiophene) with a View to the Fabrication of a Highly Nonlinear Waveguide
}

\author{
K. Messaad ${ }^{\mathrm{a}}$, D. Bosc ${ }^{*}$,, S. Haesaert ${ }^{\mathrm{a}}$, M. Thual ${ }^{\mathrm{a}}$, F. Lari ${ }^{\mathrm{b}}$, G. Froyer ${ }^{\mathrm{b}}$, V. Montembault ${ }^{\mathrm{c}}$ and \\ F. Henrio
}

\author{
${ }^{a}$ Laboratoire FOTON, UMR CNRS 6082, CCLO, ENSSAT BP 80518, 22305 Lannion Cedex, France \\ ${ }^{b}$ Institut des Matériaux Jean Rouxel, Université de Nantes, UMR CNRS 6502, BP 32229, 44322, Nantes, Cedex 3 , \\ France
}

${ }^{c}$ UCO2M, UMR CNRS 6011, Université du Maine, Avenue O. Messiaen, 72085 Le Mans Cedex 9, France

\begin{abstract}
In order to take advantage of the very high nonlinear susceptibility of conjugated polymer materials, Poly(3AlkylThiophene)s, P3AT, were synthesized in the laboratory. The physical, thermomechanical and linear optical properties of synthesized P3AT have been investigated and the first experimental attempts at creating nonlinear optical waveguides and determining their characteristics are presented. After synthesizing P3AT, the relationships between polymer chain characteristics and mechanical properties are investigated to see if the polymer is suitable for optical waveguide process technology. We also examine the optical attenuation of the synthesized material, a crucial factor in anticipating the relative opacity of the future component. For the first time we present the absorption spectrum of 3-Octylthiophene molecules in the Near Infra-Red (NIR) region that suggests optical losses for the material are about $0.6 \mathrm{~dB} . \mathrm{cm}^{-1}$ at 1550 $\mathrm{nm}$. Next we examined several waveguide structures such as ridge, buried and Strip Loaded WaveGuides (SLWG) based on P3AT material. For the buried waveguides, we have observed the signal transmission and in our opinion the low optical transmission of P3AT ridge and SLWG could be attributed to extrinsic losses (mainly scattering) due to both the remaining insoluble products in the polymer and to the poor adhesion between optical layers.
\end{abstract}

PCAS: 78.20.Ci, 78.30.Jw, 78.40.Me, 42.82.Cr, 42.70.Jk

Keywords: Poly(thiophene), chemical synthesis, physical properties, optical losses, waveguide.

\section{INTRODUCTION}

For very high data transmission rate systems, it is essential to process the signal in an all-optical manner. In recent years, different classes of materials have been extensively studied in the quest to develop devices for the next generation of all-optical communications networks. Of these, $\pi$ conjugated organic materials with nonlinear optical (NLO) properties [1] have attracted a great deal of interest.

The strong $\pi$ electron conjugation of these materials is a crucial factor in attaining high nonlinearities. Indeed, large effective conjugation length leads to high third-order susceptibility $\chi^{(3)}$. As a result the nonlinear refractive index, $n_{2}$, is enhanced. [2]:

This index (so-called Kerr coefficient) is related to $\chi^{(3)}$ by

$n_{2}\left(\mathrm{~cm}^{2} . W^{-1}\right)=\frac{12 \pi^{2}}{n_{0}^{2} c} 10^{7} \chi^{(3)}(e s u)$

$n_{2}=\frac{0.0395}{n_{0}^{2}} \chi^{(3)}(e s u)$

*Address correspondence to this author at the Laboratoire FOTON, UMR CNRS 6082, CCLO, ENSSAT BP 80518, 22305 Lannion Cedex, France;

E-mail: dominique.bosc@enssat.fr
In conjugated polymers, $n_{2}$ can be 4 orders of magnitude larger than that in silica (for comparison, the nonlinear refractive index values of some mineral and organic materials are listed in Table $\mathbf{1}$ ).

Table 1. Nonlinear Refractive Index Values of Some Mineral and Organic Materials

\begin{tabular}{|l|c|c|c|}
\hline \multicolumn{1}{|c|}{ Material } & $\lambda(\mathbf{n m})$ & $\begin{array}{c}\boldsymbol{n}_{2} \mathbf{x 1 0} \mathbf{1}^{-16} \\
\left(\mathbf{c m}^{\mathbf{2}} \cdot \boldsymbol{W}^{-\mathbf{l}}\right)\end{array}$ & Ref. \\
\hline \hline $\mathrm{SiO}_{2} \mathrm{SMF}$ & 1550 & 2.6 & {$[3]$} \\
\hline GaAs bulk & 1064 & -330 & {$[4]$} \\
\hline $\mathrm{As}_{2} \mathrm{~S}_{3}$ waveguide & 1550 & 292 & {$[5]$} \\
\hline $\begin{array}{l}\text { Poly(3-OctylThiophene) RegioIrregular } \\
\text { films }\end{array}$ & 1540 & 1470 & {$[6]$} \\
\hline $\begin{array}{l}\text { Poly(3-HexylThiophene) RegioRegular } \\
\text { films }\end{array}$ & 1550 & 2930 & {$[7]$} \\
\hline PMMA functionalized with DR1* films & 1320 & -3600 & {$[8]$} \\
\hline Poly(DiAcetylene) bulk & 1500 & 9000 & {$[9]$} \\
\hline Derivative of Poly(Thiophene) films & 1500 & 10000 & {$[10]$} \\
\hline $\begin{array}{l}\text { Polyurethane containing fullerenes } \mathrm{C}_{60} \\
\text { films }\end{array}$ & 1550 & 20000 & {$[11]$} \\
\hline Poly(p-Phenylene Vinylene) films & 1500 & 20000 & {$[12]$} \\
\hline
\end{tabular}

* PMMA: Poly(MethylMethAcrylate),

DR1: Disperse Red 1. 
Such large values of $n_{2}$ for conjugated polymers would be of advantage in obtaining compact all-optical processing devices at low light intensities. Besides large nonlinearities, conjugated polymers possess ultra-fast response times ( $<$ picosecond), transparency in the NIR region and good environmental stability.

However, among the articles in the literature, to the best of our knowledge only a very few attempts have been reported about creating all-optical devices based on fully conjugated polymer waveguides [13]. It seems that the main difficulty remains in processing singlemode waveguides with this class of materials. The interest in our work arises from two points: firstly, the material properties must be tailored according to the conditions of waveguide fabrication, (such as sufficient solubility in common solvents as well as good processability into films and three-dimensional structures by standard techniques), secondly, lowering the optical attenuation, due both to the material itself and to the waveguide processing.

The Alkyl groupement grafted on Thiophene main chain in the Poly(3-AlkylThiophene)s ensures some solubility and filmability, instead of the other conjugated polymers and moreover its synthesis seems easy to be performed. For these reasons this kind of polymer was chosen for this study. Thus in this paper, we report firstly on investigations into P3AT, (Poly(3-OctylThiophene) and Poly(3-HexylThiophene), noted hereafter P3OT and P3HT respectively) properties, in order to fabricate a P3AT singlemode waveguide by standard photolithography techniques. We describe also the chemical synthesis of P3OT in our laboratory with the aim of producing sufficient quantities of soluble material to develop waveguide technology. Then, we show the physical, thermomechanical and linear-optical properties of synthesized P3OT and the first experimental attempts at singlemode three-dimensional structures fabrication.

\section{SYNTHESES AND CHARACTERIZATIONS}

In order to study both the fabrication of P3OT threedimensional structures and the polymer's various properties, we need sufficient quantities of suitable soluble material. Since the commercially available P3OT is very expensive and sometimes not soluble as we have observed, we have decided to synthesize the polymer in our laboratory to perform all the characterizations and the technological attempts. We have also purchased a small quantity of P3OT and P3HT from Aldrich to use for some measurements.

\section{Polymerization of 3-OctylThiophene}

The synthetic route we have used to polymerize the monomer 3-Octylthiophène (3OT) is the traditional $\mathrm{FeCl}_{3}$ method shown as Scheme 1, in which $3 \mathrm{OT}$ is oxydatively polymerized by $\mathrm{FeCl}_{3}$ in anhydrous chloroform $\left(\mathrm{CHCl}_{3}\right)$ [14].

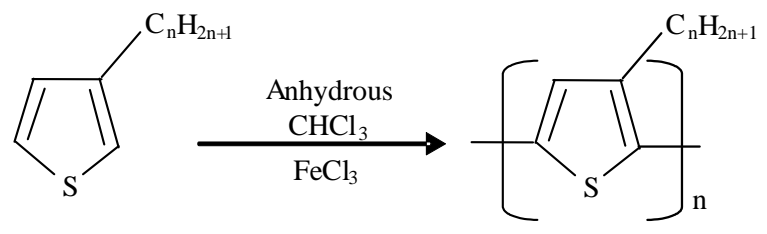

Scheme 1. Chemical synthesis of Poly(3-AlkylThiophene) by $\mathrm{FeCl}_{3}$ method, $\mathrm{C}_{\mathrm{n}} \mathrm{H}_{2 \mathrm{n}+1}$ : Alkyl chain ( $\mathrm{n}=6$ for Hexyl, $\mathrm{n}=8$ for Octyl).
In the $\mathrm{FeCl}_{3}$ method, the coupling of the adjacent monomers is not chemically controlled, so the resulting P3OT is called regio-irregular (RIRg) P3OT. In other specific synthetic methods [15], it is possible to chemically control the structural regularity of organic material so that to obtain a regio-regular $(\mathrm{RRg})$ polymer, however due to their complex experimental procedures, RRg P3OT synthesis cannot be considered in our laboratory. Even if the nonlinearities of RIRg P3AT polymers are slightly lower than those of RRg, they exhibit better NLO properties than those of inorganic materials (Table 1).

Several syntheses were carried out under different conditions: temperature; reaction time and the way of polymer extraction, in order to improve the polymer solubility. The detailed reaction is described as follows: first, dried $\mathrm{FeCl}_{3}$ $(0.15 \mathrm{~mol})$ is weighed in a reaction vessel and kept under nitrogen.

Anhydrous $\mathrm{CHCl}_{3}(200 \mathrm{ml})$ is added to the vessel and then the $3 \mathrm{OT}$ monomer $(0.038 \mathrm{~mol}$ dissolved in $20 \mathrm{ml}$ of $\left.\mathrm{CHCl}_{3}\right)$ is dropwise added. The mixture is held at reaction temperature and stirred under nitrogen for several hours.

At the end of the reaction, the mixture is washed with methanol- $\mathrm{HCl}$ and de-doped by monohydrate hydrazine. The first syntheses were done at $50^{\circ} \mathrm{C}$ by monomer addition to the mixture over a period of $50 \mathrm{~min}$. The mixture was stirred under nitrogen for 7 hours.

These syntheses have led to completely insoluble polymer. Following this, the reaction was conducted at room temperature and the period of monomer addition reduced to 10 min. These conditions allowed us to obtain P3OT with a suitable solubility in common solvent for our applications. The polymerisation conditions for the most soluble P3OT (with a concentration ranging from $150 \mathrm{~g} / \mathrm{l}$ ) are listed in Table 2 .

Table 2. Chemical Reaction Conditions Chosen in Laboratory

\begin{tabular}{|c|c|c|}
\hline $\begin{array}{c}\text { FeCl } 3 \text { /3OT } \\
\text { (Molar Ratio) }\end{array}$ & $\begin{array}{c}\text { Reaction } \\
\text { Temperature }\end{array}$ & $\begin{array}{c}\text { Monomer Dropwise } \\
\text { Duration }\end{array}$ \\
\hline \hline 4 & $20\left({ }^{\circ} \mathrm{C}\right)$ & $10 \mathrm{mn}$ \\
\hline Reaction atm. & Polymer Extraction & Reaction Time \\
\hline \hline $\mathrm{N}_{2}$ & with $\mathrm{HCl}+$ Methanol & $7 \mathrm{~h}$ \\
\hline
\end{tabular}

The $\mathrm{FeCl}_{3}$ method is widely used to polymerize 3AlkylThiophene because it produces high molecular weights, which are needed for good mechanical properties, but we have observed that in spite of maintaining identical reaction conditions the reproducibility of this method is low, especially on the polymer solubility that sometimes is too low. After several experimentations, in particular by changing polymerization parameters (time, temperature), we have improved the yield of this method up to $90 \%$. By elemental analysis, synthesized P3OT reveals levels of $\mathrm{Fe}$ impurities between 113 and $288 \mathrm{ppm}$ for the most soluble synthesized polymers, instead of $>1000 \mathrm{ppm}$ for the former ones. A small content of $\mathrm{Fe}$ avoids some optical losses by scattering. 
To develop waveguides, the synthesized polymer must have good film-forming ability. A study of film deposition conditions by spin-coating method has allowed us to produce homogeneous films of sufficient thickness $(>2.5 \mu \mathrm{m}$ measured by $\mathrm{m}$-lines technique) out of polymer solutions $(150 \mathrm{~g} / \mathrm{l}$ in toluene filtered $0.2 \mu \mathrm{m}$ ) onto silica substrates (the conditions used are: spin speed $=1500 \mathrm{rd} / \mathrm{min}$, spin time $=10 \mathrm{~s}$ ). It is essential now to have a good knowledge of synthesized P3AT physical and thermomechanical characteristics. This will allow us to engineer waveguides. We describe below the different methods that we used to measure the characteristics of the P3AT polymers and then results are discussed.

\section{Characterizations for P3AT}

P3AT polymer has been characterized as bulk, pure films or in solution in order to understand its different properties better. Molecular weights of P3ATs and corresponding polydispersity indexes were determined by Size Exclusion Chromatography (SEC) on a Varian chromatograph calibrated by polystyrene standards and using THF as an eluent. UV-VIS and NIR absorption spectra of synthesized polymer both in dilute chloroform solution $(0.05 \mathrm{~g} / \mathrm{l}$ filtered at 0.2 $\mu \mathrm{m})$ and in thin films spin-coated onto glass substrates were recorded in the wavelength range of 300 to $1700 \mathrm{~nm}$ with a Perkin-Elmer two-beam spectrophotometer (Lambda 900), in order to have qualitative evaluation of the synthesized polymer conjugation length and material losses respectively. In these spectroscopic analyses, the reference beam passed through the air. Regio-regularity characteristics of the material were measured by $\mathrm{NMR},{ }^{1} \mathrm{H}$ and ${ }^{13} \mathrm{C}$ spectroscopy. Refractive indexes and thicknesses of spin-coated films were measured by m-lines techniques on a Metricon model 2010. All the above measurements were made at room temperature. Finally a thermal analysis was carried out using P3AT bulk material (a few hundred micrometers of thickness) on a Perkin-Elmer TA instrument from $20^{\circ} \mathrm{C}$ to $200^{\circ} \mathrm{C}$ using a heating rate of $5^{\circ} \mathrm{C} / \mathrm{min}$.

\section{RESULTS AND DISCUSSION}

\section{Solubility and Molecular Weight}

SEC results are listed in Table 3. They indicate that the less soluble synthesized P3OT has a lower weight-average molecular weight $(\mathrm{Mw})$ than that of the most soluble one however its chromatogram shown in Fig. (1), includes at least two molecular distributions. That is probably an indication of the existence of impurities or fractions of strongly modified polymer in the analyzed sample. In comparison with SEC of RIRg P3HT (purchased from Aldrich with high solubility $\sim 200 \mathrm{~g} / \mathrm{l}$ ), we observe that its chromatogram shows only one molecular distribution and the corresponding $\mathrm{Mw}$ is in the same range as that of the soluble synthesized polymer. With these relatively high $\mathrm{Mw}$ values, we can also expect that the synthesized material will have good mechanical properties. Thermomechanical analysis of these polymers will be presented later.

Moreover, the effective conjugation length of P3AT could be related to the number of 3-AlkylThiophene rings composing an uninterrupted segment of aromatic units. Here, SEC results of synthesised polymer suggest that the analyzed P3OT sample contains around 600 of 3-OctylThiophene rings; however, the conjugated states are strongly affected by polymerisation defects and impurities in the polymer. That is to say that the effective conjugation length of synthesised polymer is inevitably much lower than that predicted by the SEC.

Table 3. Comparison of Solubility and Average Molecular Weight Obtained by Size Exclusion Chromataography for Different Poly(3-Alkyl Thiophene)

\begin{tabular}{|c|c|c|c|c|}
\hline Polymer & Mn (g/mole) & $\underset{(\mathrm{g} / \mathrm{mole})}{\mathbf{M w}}$ & PDI & Comments \\
\hline $\begin{array}{l}\text { Insolub.RIRg } \\
\text { P3OT * }\end{array}$ & 23700 & 75700 & 3.2 & $\begin{array}{l}2 \text { molecular } \\
\text { distributions }\end{array}$ \\
\hline $\begin{array}{c}\text { Soluble RIRg } \\
\text { P3OT }\end{array}$ & 40700 & 121600 & 3.0 & \\
\hline $\begin{array}{c}\text { RIRg P3HT } \\
\text { (from Aldrich) }\end{array}$ & 29700 & 117000 & 3.9 & $\begin{array}{c}\text { One } \\
\text { distribution }\end{array}$ \\
\hline
\end{tabular}

Mn: number-average molecular weight; Mw: weight-average molecular weight; PDI: polydispersity index.

* Insoluble (polymer concentration $<50 \mathrm{~g} / \mathrm{l}$ ) to produce thick film.
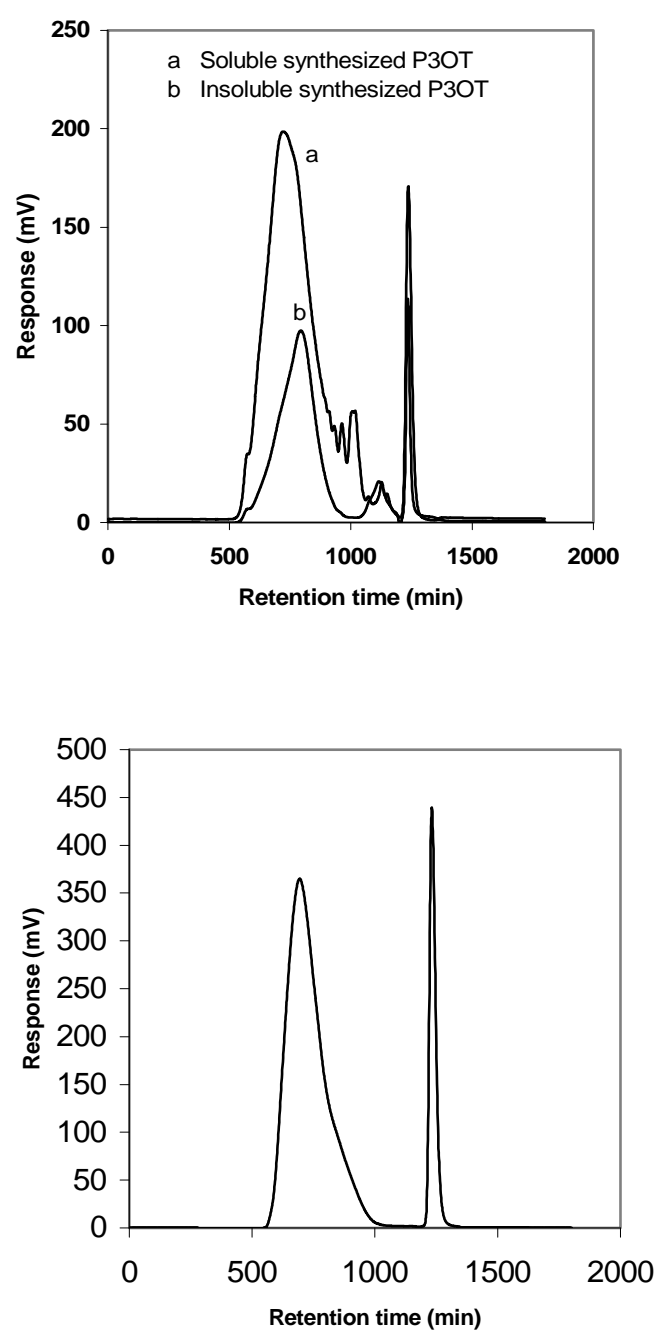

Fig. (1). Size Exclusion Chromatograms of RIRg P3AT: (top) Synthesized P3OT, (bottom) P3HT(purchased). The retention time is inversely proportional to the molecular weight and the response in the vertical axis is relative to the number of molecules. 


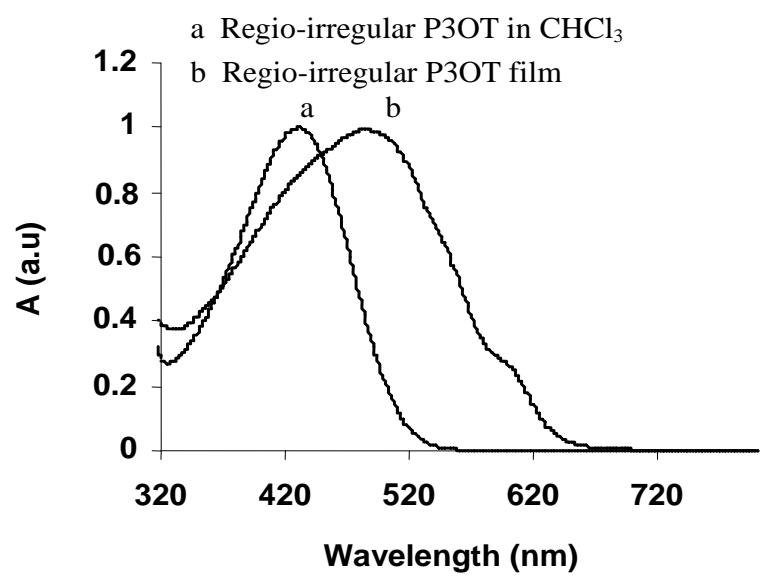

(I)

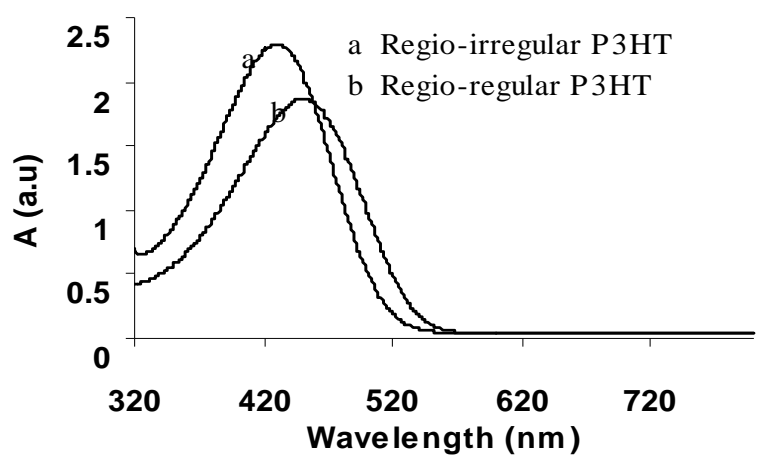

(II)

Fig. (2). UV-VIS spectra of P3AT: (I) regio-irregular synthesized $\mathrm{P} 3 \mathrm{OT}$ in $\mathrm{CHCl}_{3}$ solution and thin film (II) regio-regular and regioirregular $\mathrm{P} 3 \mathrm{HT}$ in $\mathrm{CHCl}_{3}$ solution.

\section{UV-VIS Spectroscopy}

As is well known, the increase of effective conjugation length in $\pi$-conjugated systems leads to a decrease in the optical gap energy accompanied by an increase in the third order nonlinear susceptibility $\chi^{(3)}$ value. The UV-VIS absorption spectra of synthesized P3OTs in both $\mathrm{CHCl}_{3}$ diluted solutions and thin films (spin-coated onto glass substrates $0.5 \mu \mathrm{m}$ of thickness) were measured and are shown in Fig. (2). The solution of P3OT in $\mathrm{CHCl}_{3}$ exhibits an absorption peak, assigned to the $\pi-\pi^{*}$ transition, at $430 \mathrm{~nm}$, while it is measured at $485 \mathrm{~nm}$ for the P3OT thin film. This red shift in the maximum of absorption could be attributable to an increase in the polymer co-planarity. So the repeat units in the main chain are in a planar conformation in the solid film compared to the P3OT in solution where the disorder allows the repeat units to twist away from planarity and hence increase the band gap [16]. In order to observe the influence of regio-chemistry control on the UV-VIS absorption spectra, we have tried to measure the UV-VIS absorption spectra of RRg P3OT (purchased from Aldrich) in diluted $\mathrm{CHCl}_{3}$ solutions. Unfortunately the purchased RRg P3OT was fully insoluble and for this reason we have recorded the spectra of both purchased RIRg and RRg P3HT (> $98 \%$ Head to Tail) in $\mathrm{CHCl}_{3}$ solutions. A red shift of about $24 \mathrm{~nm}$ in the maximum of absorption is clearly observed for the RRg P3HT in comparison with RIRg P3HT which indicates the increase in the conjugation length due to the regio-chemistry control of the polymer.

We note that no significant red shift is observed in the absorption peak for RIRg P3AT in solutions with different side chain lengths. The wavelength at maximum is $430 \mathrm{~nm}$ for RIRg P3OT and P3HT in $\mathrm{CHCl}_{3}$ solutions measured in our laboratory that is close to the lambda max of $436 \mathrm{~nm}$ for RIRg Poly(3Alkyl=Butyl, Hexyl, Octyl and DodecylThiophene) in $\mathrm{CHCl}_{3}$ solutions synthesised by R. D. McCullough et al. by the $\mathrm{FeCl}_{3}$ method [17].

\section{NMR Spectroscopy}

It is important to have some knowledge about the structural regio-regularity degree of synthesised P3OT. It was reported that the $\chi^{(3)}$ value is strongly dependent on the Head to Tail - Head to Tail (HT-HT) ratio in the polymer, that is to say that when the polymer is predominately HT-HT regiocontrolled, it leads to co-planar Thiophene chains where the limiting factors of the electronic conjugation are reduced. So, some authors [7] reported that for P3HT very thin films with a $30 \%$ HT-HT coupling, $\chi^{(3)}=2.71 \times 10^{-12}$ esu, $\left(\mathrm{n}_{2} \sim 5 \times 10^{-14}\right.$ $\left.\mathrm{cm}^{2} / \mathrm{W}\right)$ whereas it becomes $27 \times 10^{-12}$ esu $\left(\mathrm{n}_{2} \sim 5 \times 10^{-13}\right.$ $\mathrm{cm}^{2} / \mathrm{W}$ ) for a $98.5 \%$ HT-HT coupling in the P3HT (using the Third Harmonic Generation, THG method with fundamental wavelength at $1550 \mathrm{~nm}$ ). Synthesized RIRg P3OT polymer was measured by NMR spectroscopy, the spectrum being shown in Fig. (3). The chemical shifts around $7 \mathrm{ppm}$ are due to aromatic hydrogen in the ring. Four peaks at 6.98 , $7.00,7.03$ and $7.05 \mathrm{ppm}$ are the signals of four different modes and the dominant one at $6.98 \mathrm{ppm}$ is assigned to the HT-HT couplings [18]. Here the differential intensity of these peaks indicates that HT-HT ratio is in the range of 68 $\%$. Thus we could expect the $\chi^{(3)}$ value to be probably in the range of a few $10^{-12}$ esu.

\section{NIR Spectroscopy}

Intrinsic attenuation in polymer is a deciding factor in the potential transmissibility of organic waveguides. It is mainly due to electronic transition $\left(\pi \rightarrow \pi^{*}\right)$ occurring in the visible region, to scattering and to $\mathrm{C}-\mathrm{H}$ bond vibration in the NIR region. In order to estimate the P3AT attenuation at the wavelength of interest $(1550 \mathrm{~nm})$, we have carried out NIR spectroscopic analysis on purchased RIRg P3HT and synthesized RIRg P3OT. As an example, Fig. (4) illustrates the absorbance spectra of purchased $\mathrm{P} 3 \mathrm{HT}$ in $\mathrm{CHCl}_{3}$ solutions filtered at $0.2 \mu \mathrm{m}$ for different concentrations and using the same glass cell length of $2 \mathrm{~cm}$. The attenuation coefficient of the polymer solution $\left(\varepsilon_{\mathrm{sol}}\right)$ in the cell can be given by the relation:

$\left.\varepsilon_{\text {sol }}=\frac{1}{L} \times \operatorname{Ln} \frac{T_{1}^{2} T_{2}^{2}}{\frac{I_{T}}{I_{0}}} \mathrm{~cm}^{-1}\right)$

This coefficient can be expressed in $\mathrm{dB} . \mathrm{cm}^{-1}$ by:

$\alpha_{\text {sol }}\left(\mathrm{dB} \cdot \mathrm{cm}^{-1}\right)=4.34 \times \varepsilon_{\text {sol }}\left(\mathrm{cm}^{-1}\right)$

where: $L$ is the length of the glass cell. In order to take into account the reflection losses, the transmission coefficients $T_{l}$ 


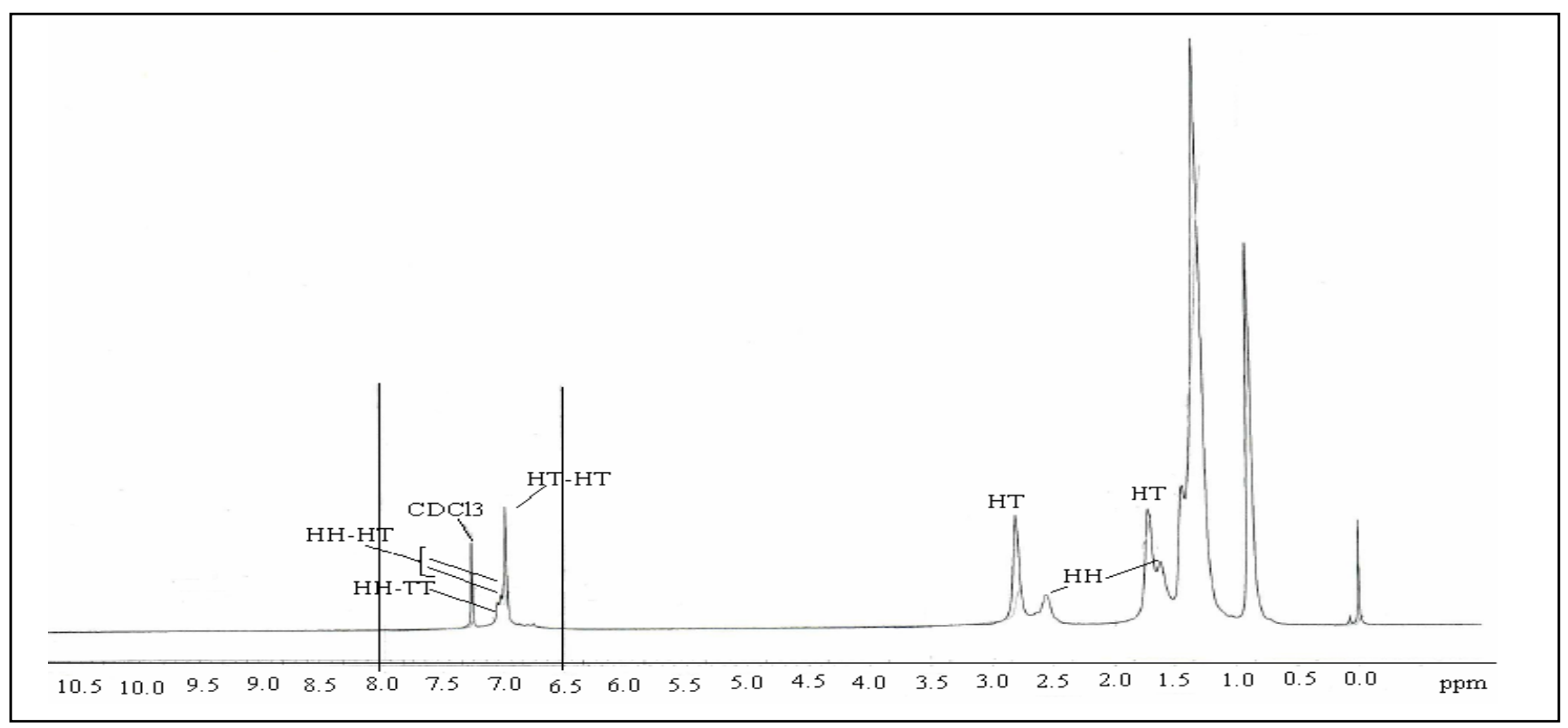

Fig. (3). ${ }^{1} \mathrm{H}$ NMR spectrum of synthesized P3OT.

and $T_{2}$ are introduced in the relation (2). $T_{1}$ is the intensity transmission coefficient at the air/glass surface; $T_{2}$ is the intensity transmission coefficient at the glass/solution surface and $\frac{I_{T}}{I_{0}}$ is the transmittance of the cell containing polymer solution. This relation can be used for calculating the attenuation in transmission windows of the polymer.

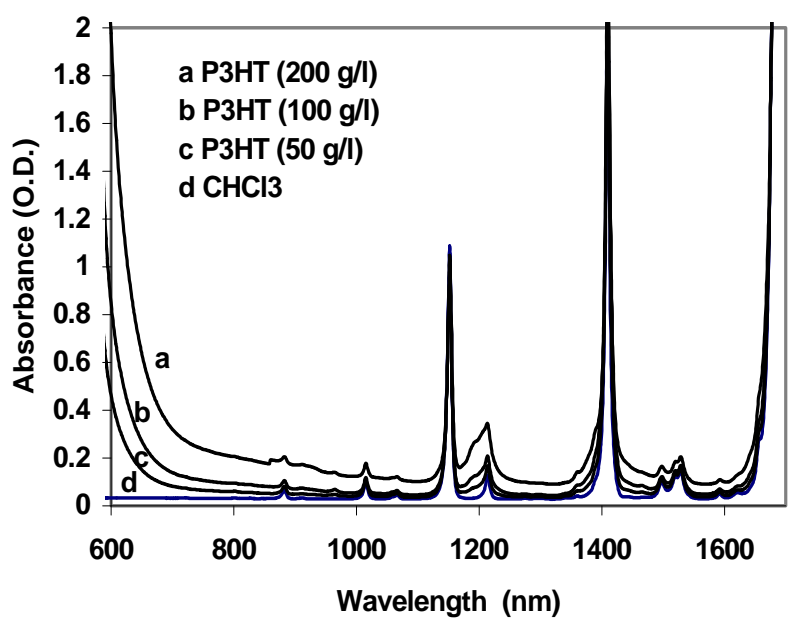

Fig. (4). NIR absorbance spectra of $\mathrm{CHCl}_{3}$ and purchased P3HT in $\mathrm{CHCl}_{3}$ solutions for different ranging concentrations.

We can estimate the attenuation coefficient of pure polymer (without solvent) by measuring $\alpha_{\text {sol }}\left(\mathrm{dB} \cdot \mathrm{cm}^{-1}\right)$ for different molar ratios of polymer using equation (3). For each solution, the molar ratio of polymer is given by $x_{\text {polymer }}=\frac{N_{\text {polymer }}}{N_{\text {polymer }}+N_{\text {solvent }}}$, (with $N_{\text {solvent }}$ and $N_{\text {polymer }}$ being the molar numbers of the solvent and of the monomer units in the polymer respectively).
The $T_{2}$ coefficient is also a function of the solution index and consequently it depends on $x_{\text {polymer }}$, however it can be fixed without any strong deviations. The extension of $\alpha_{\text {sol }}$ at $x_{\text {polymer }}=1$ enables us to have an indication of attenuation in $\mathrm{dB} . \mathrm{cm}^{-1}$. This method was previously validated by measuring intrinsic attenuation of PMMA (Poly-MethylMethAcrylate) in solution by the same method [19] and compared with bulk PMMA (rod) attenuation, we measured losses around 0.8 dB. $\mathrm{cm}^{-1}$.

In the case of P3AT the method seems to be less accurate, however we can expect from Fig. (5) the attenuation around $\sim 4 \mathrm{~dB} \mathrm{~cm}^{-1}$ at $1550 \mathrm{~nm}$ for P3HT. In comparison, we have measured the synthesized filtered P3OT by the same method and we found an attenuation of $\sim 5 \mathrm{~dB} \cdot \mathrm{cm}^{-1}$ at the same wavelength. The excess of losses can be attributed to both scattering of light due to small insoluble particles in the polymer solution and to an unexpected absorption band around $1500 \mathrm{~nm}$ that could be the result of traces of linked water or alcohol.

As the monomer and polymer units are chemically similar we have examined the absorption spectra in the NIR domain of 3OT pure monomer in different cells lengths (spectra on Fig. (6)). 3OT absorbance spectra shows 3 kinds of absorption bands mainly due to the overtone of $\mathrm{C}-\mathrm{H}$ bound. Containing aromatic and aliphatic groups, in 3OT monomer, the fundamental vibration due to stretching $\mathrm{C}-\mathrm{H}$ bound occurs at around $3240 \mathrm{~nm}$. From the spectra, the second overtone vibration is observed around $1640 \mathrm{~nm}$, the third harmonic around $1200 \mathrm{~nm}$ and we can also observe an intermediate broad-band around $1400 \mathrm{~nm}$ which is a combination band due to several modes of vibrations. Between these absorption bands a transmission window can be exploited between $1540 \mathrm{~nm}$ and $1580 \mathrm{~nm}$. Then using equation (3), we have measured intrinsic losses for 3OT monomer in the range of $0.6 \mathrm{~dB} . \mathrm{cm}^{-1}$ at $1550 \mathrm{~nm}$, which is of the same order of magnitude as PMMA bulk material attenuation. 


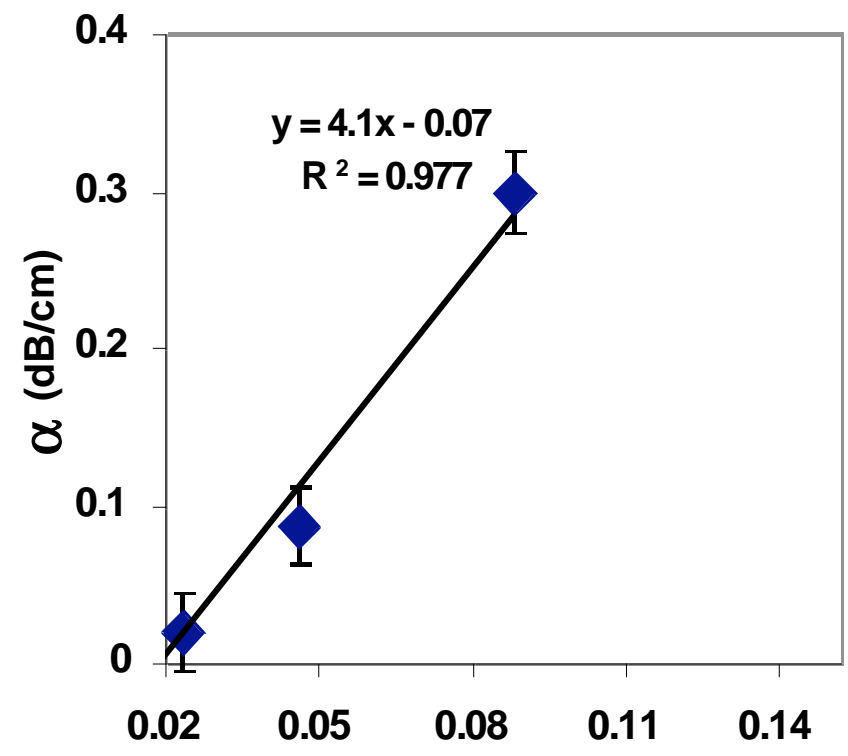

Fig. (5). Attenuation coefficient of P3HT solution versus the molar ration of polymer in solution.

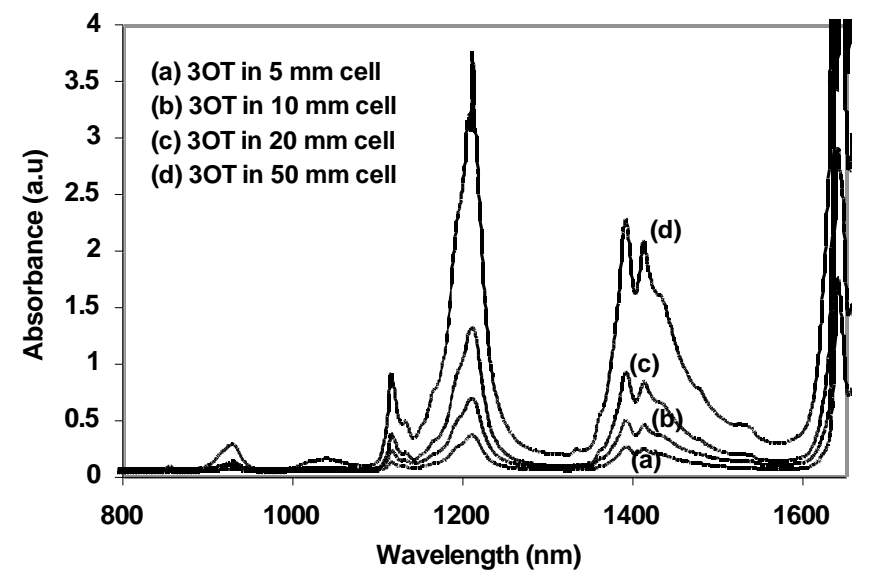

Fig. (6). NIR absorbance spectra of the 3OT monomer.

\section{Thermal Analysis}

To produce three-dimensional single mode optical structures with polymer material, it is essential in general to measure its thermomechanical properties. Thermomechanical Analyses (TMA) were conducted on synthesized P3OT samples in the temperature range of $22-200^{\circ} \mathrm{C}$ in air, where we have analyzed the change of the material's deformation with temperature. The TMA curves are shown in Fig. (7). These curves give a good idea of the glass transition temperature, $\mathrm{Tg}$, of the materials. The glass transition temperature of both P3OT and P3HT is expected to be low $(\mathrm{Tg}=$ $50.2^{\circ} \mathrm{C}$ for P3ATs determined by a Differential Scanning Calorimetry method [20]). We have already shown [21] that the value of $\mathrm{Tg}$ have to be higher than the post exposure bake temperature at $115^{\circ} \mathrm{C}$ of the photolithography process to avoid the occurring of worms-like defects.

As observed on the TMA curves, synthesized materials exhibit a $3 \%$ deformation beyond $50^{\circ} \mathrm{C}$, moreover while the partially soluble synthesized P3OT is $30 \%$ deformed at $120^{\circ} \mathrm{C}$, the most soluble synthesized polymer is $50 \%$ deformed at the same temperature. In comparison for the purchased RIRg P3HT, we observe a continuous deformation from $30^{\circ} \mathrm{C}$ to $150^{\circ} \mathrm{C}$. It seems that the synthesized polymers $\mathrm{P} 3 \mathrm{OT}$ have better thermo-mechanical properties than the P3HT. Another way to be sure that the material can withstand the waveguide processing, is to strengthen it by thermal treatment.

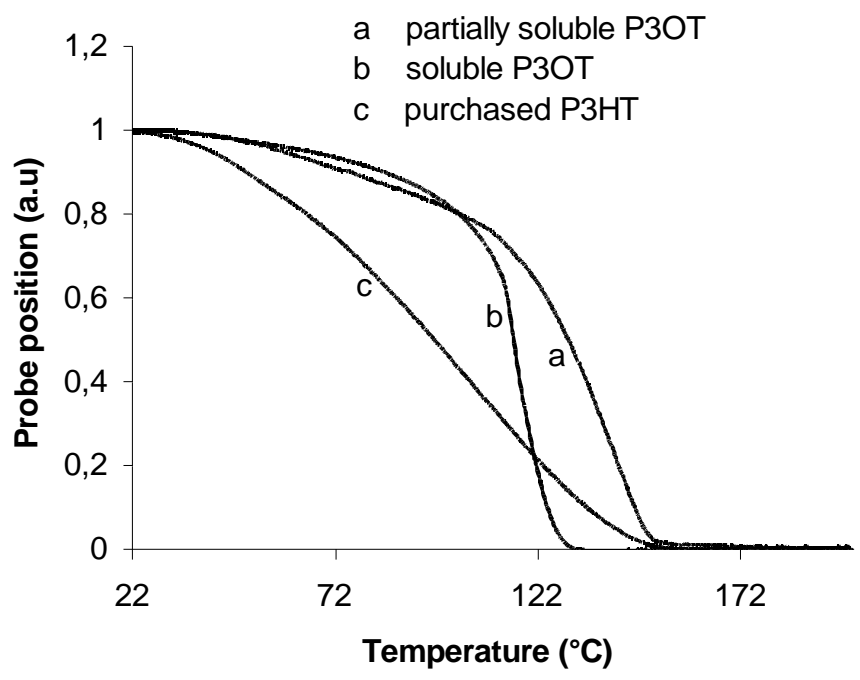

Fig. (7). TMA curves of synthesized and purchased P3AT: Sample deformation versus temperature.

Prior thermal studies on classical polymers such as PMMA, PMMI (Poly-MethylMethAcrylate Imidized) and PVCi (Poly-Vinyl Cinnamate) have shown that the Tg could be increased by a specific thermal treatment [21]. However, we noted that no significant change in the synthesized P3OT mechanical properties is observed with specific treatment (Fig. 8).

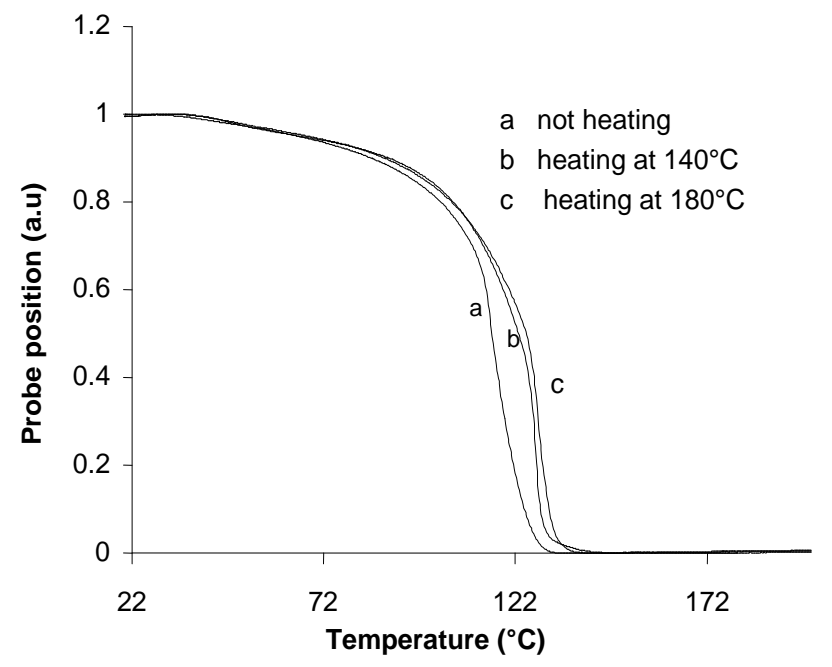

Fig. (8). TMA analysis of the most soluble P3OT. Sample deformation versus annealing heating temperature.

In conclusion of this section, the synthesized soluble P3OT exhibits relatively better thermo-mechanical properties than the purchased one. However they cannot be strengthened by heat treatment. Further attempts of waveguide fabrication are needed to confirm if these properties are actually suitable. 


\section{SINGLE MODE WAVEGUIDE EXPERIMENTS}

\section{Ridge Waveguide}

For modelling the geometric characteristics of the waveguide to yield singlemode propagation (Fig. 9), it was necessary first to measure the refractive index of synthesized material. With conventional $\mathrm{m}$-lines techniques at wavelengths of $1550 \mathrm{~nm}$ and $1330 \mathrm{~nm}$, we measured refractive indexes of $n=1.619$ and 1.623 respectively with polymer films' thickness of $2.5 \mu \mathrm{m}$ at room temperature.

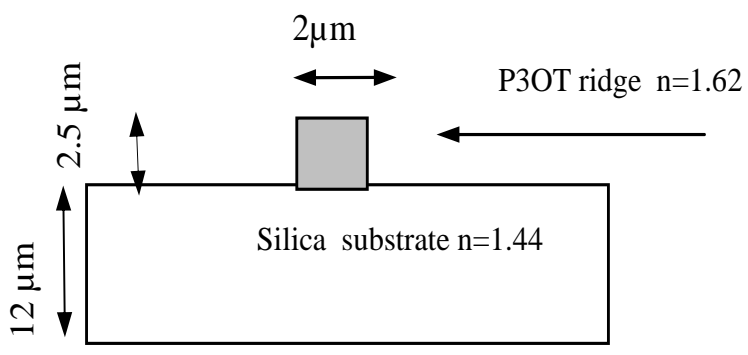

Fig. (9). Schematic representation of cross section of a ridge waveguide.

The experimental procedure used to produce a ridge waveguide by photolithography techniques conducted under clean room conditions is as follows. First, a P3OT film -core layer is spin-coated onto a cleaned silica $(\mathrm{n}=1.44$ at 1550 $\mathrm{nm})$ substrate $(12 \mu \mathrm{m}$ of silica which will form the undercladding layer on a 3 inch $\mathrm{Si}$ wafer) out of a polymer solution $(150 \mathrm{~g} / \mathrm{L}$ filtered at $0.2 \mu \mathrm{m}$ deposited in the same spincoated conditions shown above), the film is heated to $110^{\circ} \mathrm{C}$ for $15 \mathrm{~min}$ to evaporate the residual solvent (toluene), a thin layer of silica is deposited on the top of the guiding layer by sputtering (20 nm of thickness) which forms the barrier layer. A photoresist is then deposited by spin-coating. After UV exposure through a mask to define the shapes and dimensions of the ridge, the photoresist is developed, followed by a dry etching process where the ridge is finally produced.

The scanning electron microscope (SEM) photo in Fig. (10) gives pictures of the fabricated P3OT ridge. We can see that the quality of edge etching is not good enough, probably due to the poor thermomechanical properties of the polymer. Further attempts will be carried out with the new batches of P3OT when a suitable quantity is available.

\section{Strip Loaded Wave Guide}

An alternative structure to the ridge singlemode P3OT waveguide is the Strip Loaded Wave Guide (SLWG) which can be formed by loading on top of a P3OT film, a strip (thin layer) of polymer material of low refractive index. An SLWG structure would have advantages in comparison with a ridge waveguide because it does not require the etching of lateral P3OT walls. To verify optical wave guiding in such structures, we have first modelled the dimensions of the SLWG by using the Film Mode Matching method, with classic (linear) polymers including a strip of PMATRIFE (PolyMethAcrylate of TRIFluoroEthyle), $\mathrm{n}=1.40$ at $1550 \mathrm{~nm}$, onto a PMMI film as the waveguiding layer deposited on a silica substrate. Then these SLWGs were fabricated in the laboratory following the previous models. The optical characterizations showed sufficient mode confinement in the PMMI film. By butt coupling method, we measured optical losses of about $5 \mathrm{~dB} \cdot \mathrm{cm}^{-1}$, which is a promising result. SLWGs based on synthesized P3OT were then created using P3OT as the active film, PMMI ( $\mathrm{n}=1.52$ at $1550 \mathrm{~nm})$ as the strip and silica as the lower optical substrate, a schematic representation and dimensions of fabricated P3OT SLWG are given in Fig. (11) (I) and (II) respectively. Unfortunately no propagation was observed in this structure.
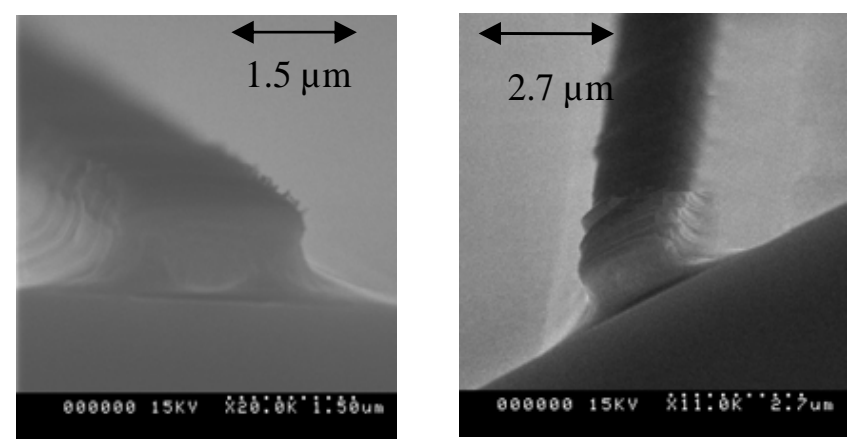

Fig. (10). Two SEM images of the first ridge based on synthesized RIRg P3OT.

We think that the propagation in P3OT SLWG is probably hindered by an excessive content of scattering particles. These particles could be solid impurities in the polymer produced during the polymerization process. They are mainly composed of partially cross-linked polymer and traces of $\mathrm{Fe}$ salts. We have tried to check this hypothesis by measuring the transmission of small P3OT rods of thickness $2.5 \mathrm{~mm}$, made by a process developed in our laboratory. High optical losses were observed confirming that these losses are mainly due to scattering of light. In the future we plan first to improve the extraction of iron salts and then to adjust the molecular weight distribution of the synthesized polymers.

\section{Buried Waveguides}

Recently, we have been able to develop another structure based on P3OT material. It consists of a polymer hollow waveguide filled with P3OT. The production of such a structure consists of two stages: first, the development of hollow waveguides with standard polymer material by photolithography techniques, secondly the filling of the hollows with P3OT by spin-coating (Fig. 12).

Using PMMI, hollow waveguides were developed onto silica optical substrates. An SEM photo of this structure is shown in Fig. (13).

The optical characterization at $1550 \mathrm{~nm}$ of the first P3OT buried waveguide enabled us to observe light propagation in P3OT for the first time as shown in Fig. (14). However, there were some defects implying losses after the samples were cleaved.

Further work must be done to improve buried waveguide structure such as improving both the confinement of light with better control of hollow waveguide dimensions, and the adhesion between P3OT and optical substrates.

\section{CONCLUSIONS}

We have synthesized in our laboratory regio-irregular P3OT by the $\mathrm{FeCl}_{3}$ method which produces high molecular 


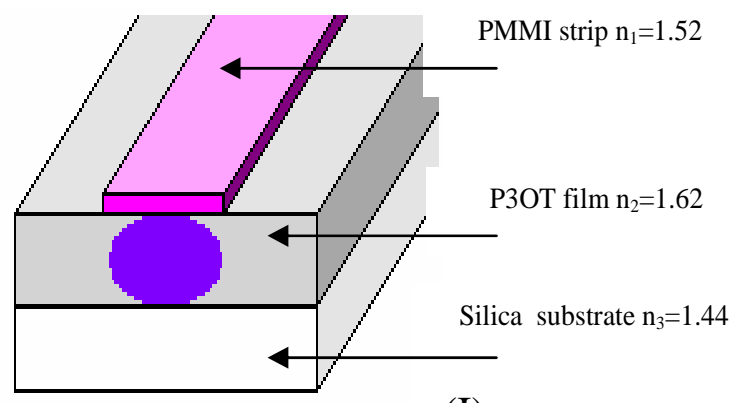

(I)

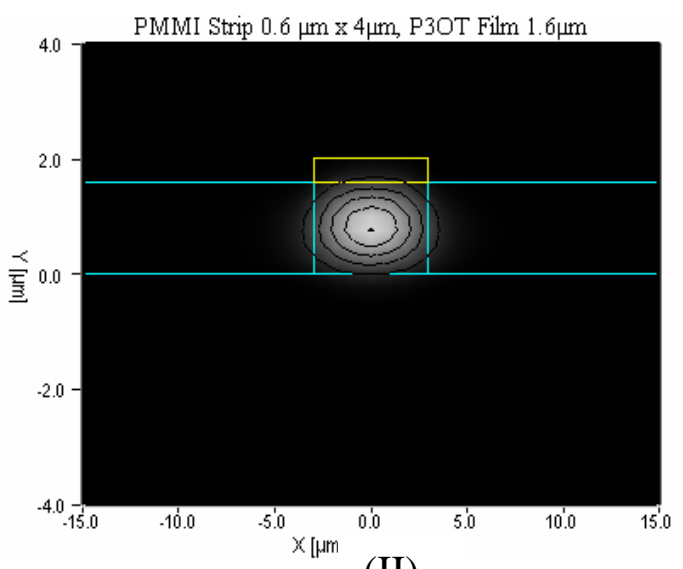

(II)

Fig. (11). (I) Schematic representation of created P3OT SLWG. (II) Dimensions and intensity profile for a singlemode P3OT SLWG.

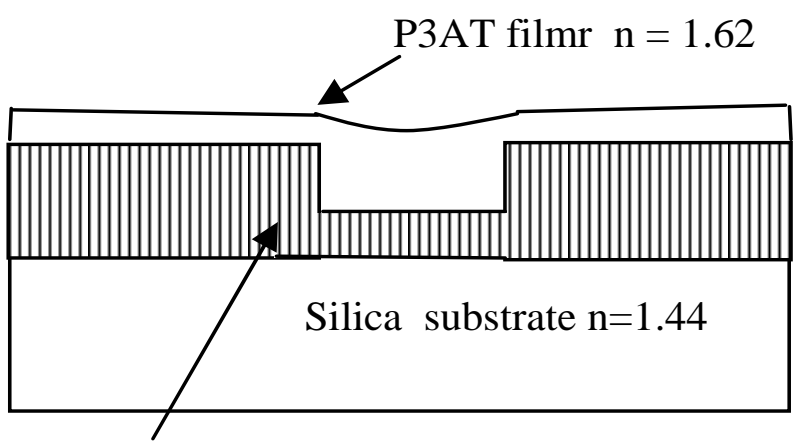

Etched optical cladding $\mathrm{n}=1.52$

Fig. (12). Cross section of a buried waveguide.

weights. $\mathrm{FeCl}_{3}$ is a simple synthetic method; however we have observed that chemical reaction conditions should be carefully controlled, in order to improve the reproducibility of the synthesis. The most soluble polymer allows us to develop highly homogeneous films of sufficient thicknesses up to $3 \mu \mathrm{m}$ for singlemode waveguide requirements. The different characterizations give us a better understanding of the synthesized polymer properties and also of the expected

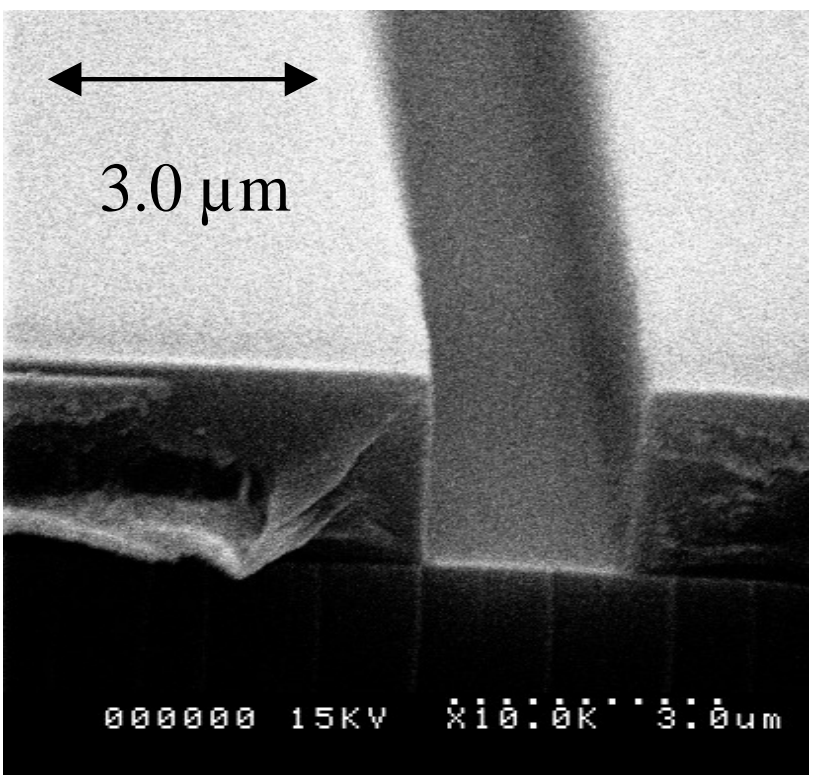

Fig. (13). SEM photo of PMMI hollow waveguide $2.5 \times 2.5 \mu \mathrm{m}^{2}$.

performance of the proposed waveguides. The P3OT synthesized material shows internal losses of about $5 \mathrm{~dB} \cdot \mathrm{cm}^{-1}$ measured in solution. That is relatively high in comparison with monomer which presents attenuation of about 0.6 $\mathrm{dB} . \mathrm{cm}^{-1}$. This could be attributable to scattering caused by impurities present in the synthesized polymer.

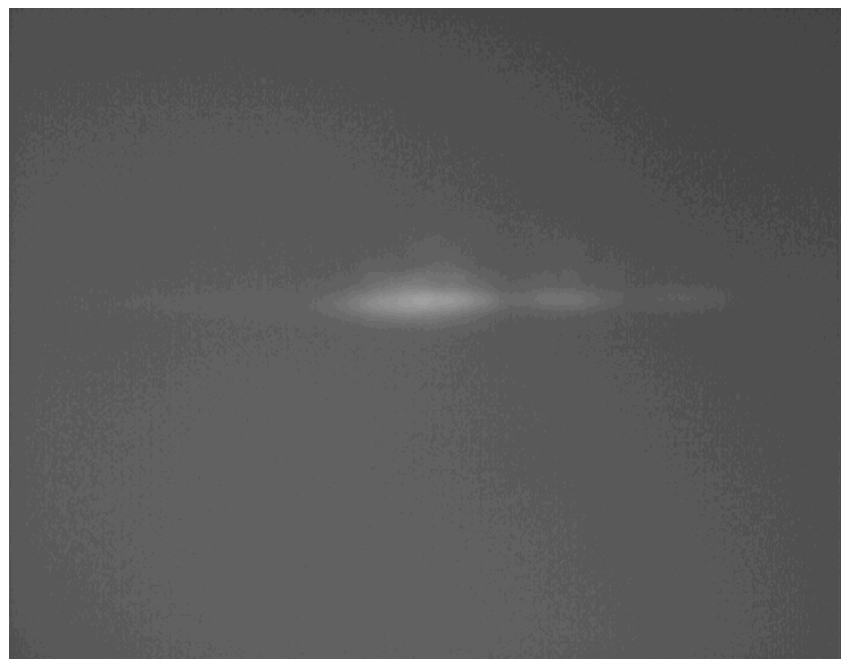

Fig. (14). Near-field photo of intensity in P3OT buried waveguide at $1550 \mathrm{~nm}$.

Because of its low thermomechanical properties, the engineering of synthesized polymer into a ridge waveguide by standard photolithography techniques leads to surface defects especially when depositing the barrier layer (silica). SLWG and buried waveguide structures seem to be better adapted to P3AT material because they do not need the etching of P3OT films.For the first time, we have observed the waveguiding of light in a buried waveguide at $1550 \mathrm{~nm}$. Further studies will concentrate on improving the material quality to be processed for both SLWG and buried waveguides.

\section{ACKNOWLEDGEMENTS}

This work was supported by the GIS FOTON sponsors, the "Région Bretagne" and the European Social Fund. The 
authors are grateful for all the scientific and technical assistance they have received from their colleagues at the CCLO. We are also grateful to Mr. Henry Hicks for his valuable help.

\section{REFERENCES}

[1] Messier J, Kajzar F, Prasad P, Ulrich D. Nonlinear optical effects in organic polymers. Eds, NATO ASI Series E. Applied Sciences, Kluwer. Dodrecht, Netherlands; 1989; p.162.

[2] Boyd RW. Nonlinear Optics. Academic press: New York; 1992.

[3] Agrawal GP. Fiber-optic Communication systems. WileyInterscience, $3^{\text {rd }}$ ed, $2002 ;$ p. 64.

[4] Gupta MC. Handbook of Photonics. CRC Press 1997; p.146.

[5] Pelusi MD, Ta'eed VG, Madden S, Choi D, Luther-Davies B, Eggleton BJ. $160 \mathrm{~Gb} / \mathrm{s}$ optical time-division demultiplexing by four wave mixing in a $5 \mathrm{~cm}$ length ultra-high nonlinear $\mathrm{As}_{2} \mathrm{~S}_{3}$ waveguide: Proceedings of ECOC 2007; 3: Wel06.3.2.

[6] Okawa H, Hattori T, Yanase A, et al. Third-order optical nonlinearities of soluble polythiophenes. Mol Cryst Liq Cryst Sci Technol Sec. B: Nonlinear Opt 1992; 3: 169-82.

[7] Kishida H, Hirota K, Wakabayashi T, Okamoto H, Kokubo H, Yamamoto T. Third-order optical nonlinearity in regio-controlled polythiophene films, Appl Phys Lett 2005; 87: 121902.

[8] Vitrant G, Reinisch R, Kajzar F. M-line spectroscopy for nonlinear characterization of polymeric waveguides. Opt Eng 1995; 34(12): 3418.

[9] Polyakov S, Yoshino F, Liu M, Stegeman G. Nonlinear refraction and multiphoton absorption in polydiacetylenes from 1220 to 2200 nm. Phys Rev 2004; B6: 9115421.

[10] Schrof W, Andreaus R, Mohwald H, Rouzouvan S, Van Keuren E, Wakebe T. Nonlinear optics of polythiophene films. Nonlinear Opt 1999; 22: 295-300.
[11] Chen Q, Kuang L, Sargent EH, Wang ZY. Ultrafast nonresonant third-order optical nonlinearity of fullerene-containing polyurethane films at telecommunication wavelengths. Appl Phys Lett 2003; 83(11): 2115-2118.

[12] Samoc M, Samoc A, Luther-Davies B. Third harmonic autocorrelation and wave mixing in a thin film of poly $(p$-phenylenevinylene. Opt Express 2003; 11(15): 1787-92.

[13] Ihlein G, Menges B, Mittler-Nher S, Osaheni JA, Jenekhe SA. Channel waveguide of insoluble conjugated polymers. Opt Mater 1995; 4: 685-9.

[14] Niemi VM, Knuuttila P, Osterholm JE, Korvola. Polymerization of 3-alkylthiophenes with $\mathrm{FeCl}_{3}$. J Polymer 1992; 33(7): 1559-62.

[15] McCullough RD, Lowe RD, Jayaraman M, Anderson DL. Design, synthesis, and control of conducting polymer architectures: structurally homogeneous poly(3-alkylthiophenes). J Org Chem 1993; 58: $904-12$.

[16] Saito F, Takeoka Y, Rikukawa M, Sanui K. Synthesis of optically active regioregular poly(thiophene). Synth Metals 2005; 153: 1258.

[17] McCullough RD. The chemistry of conducting polythiophenes. Adv Mater 1998; 10(2): 1-24.

[18] Cen TA, Wu X, Rieke RD. Regiocontrolled synthesis of poly(3alkylthiophenes) mediated by rieke zinc: their characterization and solid-state properties. J Am Chem Soc 1995; 117: 233-44.

[19] Bosc D, Maalouf A, Henrio F, Haesaert S. Strengthened polymethacrylate materials for optical waveguides and integrated functions. Opt Mater 2008; 30: 1514-20.

[20] $\mathrm{Hu} \mathrm{X,} \mathrm{Xu} \mathrm{L.} \mathrm{Structure} \mathrm{and} \mathrm{properties} \mathrm{of} \mathrm{3-alkoxy} \mathrm{substituted} \mathrm{poly-}$ thiophene synthesized at low temperature. Polymer 2000; 41: 9147 54.

[21] Bosc D, Maalouf A, Haesaert S, Henrio F. Some features of optical waveguide realization in polymer for large scale circuit integration. Appl Surf Sci 2007; 253(14): 6162-4.

This is an open access article licensed under the terms of the Creative Commons Attribution Non-Commercial License (http://creativecommons.org/licenses/by$\mathrm{nc} / 3.0 /$ ) which permits unrestricted, non-commercial use, distribution and reproduction in any medium, provided the work is properly cited. 